\title{
Akinetic mutism as a classification criterion for the diagnosis of Creutzfeldt-Jakob disease
}

\author{
Anke Otto, Inga Zerr, Maria Lantsch, Kati Weidehaas, Christian Riedemann, Sigrid Poser
}

\begin{abstract}
Objectives-Among the classification criteria for the diagnosis of CreutzfeldtJakob disease, akinetic mutism is described as a symptom which helps to establish the diagnosis as possible or probable. Akinetic mutism has been anatomically divided into two forms-the mesencephalic form and the frontal form. The aim of this study was to delimit the symptom of akinetic mutism in patients with Creutzfeldt-Jakob disease from the complex of symptoms of an apallic syndrome and to assign it to the individual forms.
\end{abstract}

Methods-Between April and December 1996, 25 akinetic and mute patients with Creutzfeldt-Jakob disease were consecutively examined. The patients were classified according to the definition of akinetic mutism by Cairns and secondly in accordance with the features constituting the complete picture of an appalic syndrome (defined by Gerstenbrand).

Results-From 25 patients with definite Creutzfeldt-Jakob disease, 24 patients showed impoverishment of speech and, after a mean duration of four (range 1.1-11.2) months, almost complete absence of voluntary movements and speech. Seven patients were classified as being mute and akinetic and assigned to the mesencephalic form whereas 13 patients were classified as apallic. One patient was mute without being akinetic and four patients were comatose.

Conclusion-Diffuse brain damage underlies akinetic mutism in patients with Creutzfeldt-Jakob disease. The term can be used as a classification criterion for the diagnosis of Creutzfeldt-Jakob disease; however, it should be applied very carefully and delimited clearly from the apallic syndrome.

(F Neurol Neurosurg Psychiatry 1998;64:524-528)

Keywords: Creutzfeldt-Jakob disease; akinetic mutism; apallic syndrome

According to the definition of Cairns et al, ${ }^{1}$ akinetic mutism describes a condition of apparent alertness along with a lack of almost all motor functions including speech, gestures, and facial expression. This definition is based on a case description of a young female patient with an epidermoid cyst of the third ventricle. Later on, the term of akinetic mutism was used in connection with other comparable clinical pictures of different aetiology and patterns of damage among which are processes of brain degeneration and circumscribed cerebral lesions, above all bilateral frontal and mesodiencephalic lesions. Several authors suggested that, when describing a complex symptomatology including dementia and a disturbance of consciousness, the diagnosis of "akinetic mutism" should be waived and instead be replaced by the term "apallic syndrome". ${ }^{2-3}$ Another approach is to use the term of akinetic mutism and to consider it as just one of several stages within a process leading to an apallic syndrome. ${ }^{4}$ Akinetic mutism has been a solid classification criterion for the diagnosis of possible and probable Creutzfeldt-Jakob disease used by the European Creutzfeldt-Jakob disease surveillance unit since 1993. However, up to now no attempt has been made to explain the use of the term akinetic mutism for the diagnosis of Creutzfeldt-Jakob disease. To give a better understanding of this term and to show the differences between akinetic mutism and an apallic syndrome, the symptoms of the patients with Creutzfeldt-Jakob disease were firstly classified according to the definition of akinetic mutism by Cairns et $a l^{1}$ and secondly in accordance with the features constituting the complete picture of an apallic syndrome.

\section{Methods}

PATIENTS

The group consisted of patients registered as suspect cases of Creutzfeldt-Jakob disease at the Department of Neurology and the Institute of Neuropathology of the Georg-AugustUniversity, Göttingen. Since June 1993206 patients were visited in the notifying hospitals by a research physician and classified as probable or definite cases of Creutzfeldt-Jakob disease. Among these patients, 110 were reported to be akinetic and mute at the time of notification to the study. Apart from medical history and a physical examination, a standardised epidemiological questionnaire was completed with the relatives of the patient containing questions about a detailed history. Further information was obtained from medical records and medical staff. Twenty five patients were selected, who had been examined by one of us personally and consecutively in the time between April and December 1996. The medical history of these 25 patients provided detailed data concerning the signs and symptoms mentioned below describing the akinetic mutism and the apallic syndrome.

CLASSIFICATION CRITERIA FOR THE DIAGNOSIS OF CREUTZFELDT-JAKOB DISEASE

Patients were classified according to the criteria of Masters et $a l^{6}$ and neuropathological 
criteria.The diagnosis of Creutzfeldt-Jakob disease is probable if the patient has had rapidly progressive dementia during the past two years, if the EEG of the patient shows periodic sharp wave complexes, and if two of the following four additional symptoms appear: (1) myoclonus; (2) visual or cerebellar symptoms; (3) pyramidal or extrapyramidal signs; (4) akinetic mutism.

The diagnosis of Creutzfeldt-Jakob disease is possible if the patient has had rapidly progressive dementia during the past two years, if two of the four above mentioned clinical signs are seen, but the EEG is atypical. If the criteria are not fulfilled another disease is presumed. For the definite category the diagnosis was confirmed neuropathologically, immunocytochemically, and by prion positive western blots.

AKINETIC MUTISM DEFINED BY CAIRNS ET $A L^{1}$

The neurological status at the time of the physical examination was classified in accordance with the first definition of akinetic mutism by Cairns et al. ${ }^{1}$ Apart from the above mentioned short description, Cairns et $a l^{1}$ delineated the condition of the patient in a state of akinetic mutism as follows: "In the fully developed state he makes no sound and lies inert, except that his eyes regard the observer steadily, or follow the movement of objects, and they may be diverted by sound. Despite his steady gaze, which seems to give promise of speech, the patient is quite mute, or he answers only in whispered monosyllables. Oft-repeated commands may be carried out in a feeble, slow, and incomplete manner, but usually there are no movements of a voluntary character." The most important features were extracted from this description and summarised as followsappearance of alertness-visual fixation of the examining person-movements of the eyes in response to auditory stimuli- movements after often repeated commands-speech /speech effort

SYMPTOMS WHICH, ACCORDING TO GERSTENBRAND 5 CONSTITUTE THE COMPLETE PICTURE OF AN APALLIC SYNDROME

The development of an apallic syndrome can be caused in two different ways ${ }^{7}$ :

Type 1

Type 1 is a progressive degeneration of the cerebrum which can affect the cortex and white matter either separately or simultaneously. The apallic syndrome represents an irreparable end stage.

Type 2

Type 2 is an acute process which leads to the loss of the entire cerebral function. This may be caused by a diffuse damage to the cerebrum or by interruption of its connecting systems to the brain stem at various levels. The apallic syndrome can appear as an end stage or a transitory syndrome. The categories worked out by Gerstenbrand $^{5}$ for the description of an apallic syndrome can be divided into clinical symptoms which are caused by a lesion of structures and systems of the cerebrum (symptoms 1-4) and into symptoms which are caused due to the loss of functional systems inhibiting the brain stem (symptoms 5-8). (1) Coma vigile, in which the patient lies in bed with eyes open but staring into the distance, is neither able to fix the eyes on objects nor to follow them (by contrast with the patient in a state of akinetic mutism). The patient cannot show any adequate motor activity to external stimuli. (2) Disturbance of the normal sleep-waking cycle. (3) Primitive patterns to sensory stimuli. External stimuli cause a generalised motor reaction of all four limbs and the trunk, which clinically corresponds to mass movements. (4) Lack of emotional reactions. (5) Abnormal position of the limbs. In some cases a flexed position is seen, in other cases a stretched position of the legs is present. (6) Oculovestibular reflexes and reflexes of position. (7) Primitive motor patterns. The primitive motor patterns can be divided into different groups according to the functional basis - for instance, the motor patterns of the oral sense (sucking-chewing automatisms), the grasping reflexes, and the mental reflexes (palmomental reflex). (8) vegetative dysregulation

\section{Results}

Altogether 25 patients were included in the study; 18 women and seven men. The mean age at disease onset was 65.8 (SD 8.5); range 44-83) years. The mean time between appearance of the first symptoms and occurrence of akinetic mutism was four (range 1.1-11.2) months. The mean duration of disease of all patients was 7.5 (range 2-17) months. The time span between occurrence of akinetic mutism and date of death was a mean of 3.5 (range 0.3-15) months.

\section{CLINICAL PRESENTATION AT THE ONSET AND IN} THE COURSE OF THE DISEASE

Seventeen patients $(68 \%)$ showed signs of a rapidly progressive dementia syndrome at the onset of the disease. Speech disorders with phonematic or semantic paraphasia, dysarthria, perseverations, and impairments in speech understanding were seen in only five cases at the onset. Pseudobulbar speech was noticed in three cases at the beginning of the disease, in two other cases it was noticed during the subsequent observation period. Akinetic mutism never appeared as an initial symptom. In the course of the disease, all patients developed dementia and mutism which often manifested itself in a reduction of spontaneous speech, construction of incomplete sentences, and single word utterances.

CLASSIFICATION ACCORDING TO MASTERS et al $l^{6}$ According to the classification of Masters et al, 22 patients were classified as probable and three as possible cases (later confirmed as definite cases by neuropathological examination). All patients had shown at least two of the four concomitant symptoms previously described which are necessary to assume the potential diagnosis of Creutzfeldt-Jakob disease. In addition, six patients presented disturbances of 
Table 1 Classification of the patients fulfilling the criteria for an akinetic mutism syndrome (according to Cairns et al ${ }^{1}$ )

\begin{tabular}{lll}
\hline$n=24$ & $n$ & $\%$ \\
\hline Appearance of alertness & 7 & 28 \\
Visual fixation of the examining person & 7 & 28 \\
Movements of the eyes in response to auditory & 7 & 28 \\
$\quad$ stimuli & & \\
Movements after frequently repeated commands & 3 & 12 \\
Spontanous speech/speech effort & 3 & 12 \\
\hline
\end{tabular}

ocular motor control; two of them had a vertical gaze palsy.

CLASSIFICATION OF THE PATIENTS ACCORDING TO THE DEFINITION AND DESCRIPTION OF THE STATE OF AKINETIC MUTISM BY CAIRNS et al ${ }^{1}$

Seven of 25 patients fulfilled the criteria of akinetic mutism developed by Cairns et $\mathrm{ll}^{1}$. These patients were awake, fixed their eyes on the examining person, and reacted to auditory stimuli by moving their eyes (table 1). At the time of the examination one patient was mute but able to walk and perform activities of daily living on his own and was therefore not assigned to a state of an akinetic mutism. In the further progression of the disease he developed an akinetic mutism.

CLASSIFICATION OF THE PATIENTS ACCORDING TO THE SYMPTOMS CONSTITUTING THE COMPLETE PICTURE OF AN APALLIC SYNDROME

(GERSTENBRAND) ${ }^{5}$

Thirteen patients who presented a special kind of impaired consciousness in the sense of a coma vigile were categorised into the complex of symptoms of an apallic syndrome. All these patients showed an impaired sleep-waking cycle and no emotions of any kind. Table 2 shows the individual symptoms. The symptoms constituting the complete picture of an apallic syndrome were applied to the seven patients who were in the state of akinetic mutism (table 3). Many of these patients showed a disturbed sleep-waking cycle and a lack of emotions. One patient responded with a smile, another looked reluctantly and was moaning. Oculovestibular reflexes and a coma vigile could not be found. All patients showed a visual fixation of the examining person. The symptoms of these patients thus differ from those present in patients with an apallic syndrome. It is striking that abnormalities of posture and primitive motor patterns occurred twice as often in patients with an apallic snydrome than in patients with akinetic mutism. These symptoms belong to the complex of symptoms 5-8 comprising disinhibited functions after a failure of higher cortical systems. Proportionally, vegetative dysregulation was found more often in patients who were in a state of akinetic mutism. At the time of investigation, four patients had already been comatose- that is, their consciousness was clouded and the sleep-waking cycle was disturbed. ${ }^{7}$ They are not included in tables 2 and 3.

\section{Discussion}

CLINICAL PRESENTATION AT THE ONSET AND IN THE COURSE OF THE DISEASE

After a mean duration of four months, akinetic mutism occurred in 24 patients. However, mutism and akinesis must not develop simultaneously. One patient was in a state of mutism and very apathic; however, he could walk and was able to perform some activities of daily living on his own. In accordance with the definition of Cairns et al this patient, despite his apathy and hypokinesia, cannot be classified as being akinetic and mute. In psychotic disorders also, which originate from a loss of motivation

Table 2 Classification of the patients fulfilling the criteria for an apallic syndrome (according to Gerstenbrand et al ${ }^{5}$ )

\begin{tabular}{|c|c|c|c|c|c|c|c|c|c|c|c|c|c|c|c|}
\hline & \multicolumn{13}{|c|}{ Patients in the state of an apallic syndrome, $n=13$ (group 2) } & \multirow[b]{2}{*}{$n$} & \multirow[b]{2}{*}{$\%$} \\
\hline & 1 & 2 & 3 & 4 & 5 & 6 & 7 & 8 & 9 & 10 & 11 & 12 & 13 & & \\
\hline 1 Coma vigile & $\mathrm{x}$ & $\mathrm{x}$ & $\mathrm{x}$ & $\mathrm{x}$ & $\mathrm{x}$ & $\mathrm{x}$ & $\mathrm{x}$ & $\mathrm{x}$ & $\mathrm{x}$ & $\mathrm{x}$ & $\mathrm{x}$ & $\mathrm{x}$ & $\mathrm{x}$ & 13 & 100 \\
\hline $\begin{array}{l}2 \text { Disturbance of the normal } \\
\text { sleep-waking cycle }\end{array}$ & $\mathrm{x}$ & $\mathrm{x}$ & $\mathrm{x}$ & $\mathrm{x}$ & $\mathrm{x}$ & $\mathrm{x}$ & $\mathrm{x}$ & $\mathrm{x}$ & $\mathrm{x}$ & $\mathrm{x}$ & $\mathrm{x}$ & $\mathrm{x}$ & $\mathrm{x}$ & 13 & 100 \\
\hline 3 Primitive patterns to sensory stimuli & $\mathrm{x}$ & $\mathrm{x}$ & & $\mathrm{x}$ & $\mathrm{x}$ & & & & & & $\mathrm{x}$ & $\mathrm{x}$ & $\mathrm{x}$ & 7 & 54 \\
\hline 4 Lack of emotional reactions & $\mathrm{x}$ & $\mathrm{x}$ & $\mathrm{x}$ & $\mathrm{x}$ & $\mathrm{x}$ & $\mathrm{x}$ & $\mathrm{x}$ & $\mathrm{x}$ & $\mathrm{x}$ & $\mathrm{x}$ & $\mathrm{x}$ & $\mathrm{x}$ & $\mathrm{x}$ & 13 & 100 \\
\hline 5 Abnormal position of the extremities & & $\mathrm{x}$ & & $\mathrm{x}$ & $\mathrm{x}$ & $\mathrm{x}$ & & & $\mathrm{x}$ & $\mathrm{x}$ & $\mathrm{x}$ & $\mathrm{x}$ & $\mathrm{x}$ & 9 & 69 \\
\hline $\begin{array}{l}6 \text { Oculovestibular reflexes and reflexes } \\
\text { of position }\end{array}$ & & & & & & & & & & & & $\mathrm{x}$ & $\mathrm{x}$ & 2 & 15 \\
\hline 7 Primitive motor patterns & & $\mathrm{x}$ & & & $\mathrm{x}$ & $\mathrm{x}$ & $\mathrm{x}$ & $\mathrm{x}$ & & $\mathrm{x}$ & $\mathrm{x}$ & & $\mathrm{x}$ & 8 & 62 \\
\hline 8 Vegetative dysregulation & $\mathrm{x}$ & & & & & & & & & & $\mathrm{x}$ & & & 2 & 15 \\
\hline $\begin{array}{l}\text { Symptoms of the individual patients } \\
\text { (n) }\end{array}$ & 5 & 6 & 3 & 5 & 6 & 5 & 4 & 4 & 4 & 5 & 7 & 5 & 7 & & \\
\hline \multicolumn{16}{|l|}{$\mathrm{x}=$ present } \\
\hline \multicolumn{16}{|l|}{ Table 3} \\
\hline & & & \multicolumn{11}{|c|}{ Patients in the state of akinetic mutism, $n=7$ (group 1) } & & \\
\hline & & & 1 & 2 & & 3 & & 4 & 5 & & 6 & 7 & & $n$ & $\%$ \\
\hline \multicolumn{16}{|l|}{1 Coma vigile } \\
\hline 2 Disturbance of the normal sleep-waki & ng c & & & & & $\mathrm{x}$ & & & $\mathrm{x}$ & & $\mathrm{x}$ & $\mathrm{x}$ & & 4 & 57 \\
\hline 3 Primitive patterns to sensory stimuli & & & & & & $\mathrm{x}$ & & & & & $\mathrm{x}$ & & & 2 & 29 \\
\hline 4 Lack of emotional reactions & & & & $\mathrm{x}$ & & $\mathrm{x}$ & & $\mathrm{x}$ & $\mathrm{x}$ & & $\mathrm{x}$ & & & 5 & 71 \\
\hline 5 Abnormal position of the limbs & & & & & & & & & $\mathrm{x}$ & & & $\mathrm{x}$ & & 2 & 29 \\
\hline \multicolumn{16}{|c|}{6 Oculovestibular reflexes and reflexes of position } \\
\hline 7 Primitive motor patterns & & & & & & & & & $\mathrm{x}$ & & & $\mathrm{x}$ & & 2 & 29 \\
\hline 8 Vegetative dysregulation & & & & & & & & $\mathrm{x}$ & & & & $\mathrm{x}$ & & 2 & 29 \\
\hline Symptoms of the individual patients (n) & & & & 1 & & 3 & & 2 & 4 & & 3 & 4 & & & \\
\hline
\end{tabular}


but not from diffuse or circumscribed cerebral lesions, such as catatonia and depression, the term should not be applied. In some of the other 24 patients, who lay motionless in bed, motor activity could also be induced by startling them through auditory stimuli. They often reacted with defensive reflexes of all four limbs and thus proved that, in a state of akinetic mutism, they lie motionless but not paralysed in bed. This aspect is also part of the definition of Cairns et al ${ }^{1}$ and Freemon. ${ }^{2}$

AKINETIC MUTISM ACCORDING TO CAIRNS et $a l^{1}$ Cairns et $a l^{1}$ describe the symptomatology of their patient with a cyst in the third ventricle with complete immobility, inability to speak, and showing adequate reactions to external stimuli. The condition of a patient with circulatory disturbances in the mesodiencephalic region is characterised similarly by Segarra. ${ }^{8}$ The patient lay motionless but not paralysed in bed, was somnolent but not comatose, calm but not mute. The akinetic state of the patient of Cairns et al could immediately be remedied by puncture of the cyst. The child could speak normally and did not show any other neurological deficiencies. At the time of the disease, the child's ability to move and speak seems to have been blocked. There are similar reports from other authors, who noted an improvement in the symptomatology of their patients. ${ }^{9-10}$ The case study of Lhermitte et $a l^{11}$ showed that some patients who are in a state of akinetic mutism can even be oriented relative to time and place and show a certain understanding of speech. They could elaborate a communication code with a patient who had developed akinetic mutism after an ischaemic lesion of the reticular formation. By hand movements she indicated as to which of the answers given in choice were correct and, for short periods during the day, she could answer with "yes" and "no". By contrast with this blockage of speech and motor activity caused by a circumscribed lesion, our patients always developed dementia during a primary degenerative process. According to Kretschmer $^{7}$ this means a quantitative reduction of cerebral performances, although cerebral functioning is preserved to a certain degree. This process often also affects speech and may entail a veritable degradation of speech. An attempt to develop a communication code with the 25 patients examined, similar to the code elaborated by Lhermitte $e t a l^{11}$ and his patient, was unsuccessful. There is a discrepancy, though, between speech production and speech understanding. One patient, in a prestage to akinetic mutism, was mute but correctly followed simple instructions. This also occurred in some of the patients who were in a state of akinetic mutism. Lebrun defines mutism as a loss of speech while a clearly better speech understanding is preserved. ${ }^{12}$ This definition is valid for patients with CreutzfeldtJakob disease. Several years after its introduction by Cairns et al, ${ }^{1}$ the term akinetic mutism was more exactly subdivided into a pathologically anatomically localised frontal form and a mesencephalic form and, in accordance with the clinical picture, into a hyperpathic and somnolent form. ${ }^{8}$ The frontal form occurs in patients with bilateral circulatory disturbances in the supply area of the anterior cerebral artery. ${ }^{2}{ }^{13-19}$ Other papers state that akinetic mutism occurred in patients with glioblastoma which had infiltrated bilaterally the rostral midline structures and medial parts of the frontal lobe. ${ }^{20}$ In various papers, examples for mesodiencephalic lesions are given-for example, in the case of a craniopharyngioma in the region of the third ventricle, ${ }^{102}$ damage to the thalamus and hypothalamus, ${ }^{22}$ a small midbrain lesion, ${ }^{23}$ lesions in the late stage of an obstructive hydrocephalus, ${ }^{24}$ and circulatory disturbances in the mesodiencephalic region. ${ }^{25}$ These lesions always go along with perceptive and cognitve deficiencies. ${ }^{3}$ Our patients would have to be assigned to the mesencephalic type. Segarra ${ }^{8}$ assigned two different clinical appearance forms to both anatomical localisations: "hyperpathic" akinetic mutism to bilateral frontal lobe damage, "somnolent" or "apathetic" akinetic mutism to the mesencephalic region. On the one hand, both forms can be distinguished by the degree of vigilance and on the other by the preservation of ocular motor control. Mesencephalic damage is typically characterised by vertical gaze palsy and ophthalmoplegia. Interestingly, six patients from the selected group showed disorders of the ocular motor control and two patients a vertical gaze palsy. Our patients would thus have to be assigned to the mesencephalic type and somnolent type of akinetic mutism. By contrast with the case descriptions mentioned above neuropathological findings in the brain of patients with Creutzfeldt-Jakob disease are not limited to the mesencephalon. On light microscopical examination, various degrees of spongiform change was observed in 189 patients examined by Brown et al. ${ }^{26}$ Lesions were typically seen in the neocortex, thalamus, basal ganglia, and cerebellum, but the comparative severity varied greatly from patient to patient and within different regions of the same brain. Therefore it seems unlikely that a correlation will be found between neuropathological patterns and the akinetic mutism in patients with Creutzfeldt-Jakob disease. Nevertheless, no attempt has not been made, yet.

APALLIC SYNDROME ACCORDING TO GERSTENBRAND ${ }^{5}$

According to Kretschmer, ${ }^{7}$ the apallic syndrome may represent the end stage of a chronic or acute process, such as a tumour disease or trauma respectively. Phases of a coma prolongé, parasomnia, and akinetic mutism may preceed a traumatic apallic syndrome which may turn into a coma during the course. The phases of a prolonged coma and parasomnia occur after development of an acute midbrain syndrome and are characterised by persistent coma and a somnolent state in which the eyes of the patient are closed. These phases do not necessarily appear in patients with a degenerative process. However, the 25 patients showed different stages. In the earliest stage of the disease, one patient was mute but not akinetic, 
seven were in a state of akinetic mutism, 13 in a subsequent stage of an apallic syndrome, and four patients in a final stage of a coma. In the whole course of the disease, there was considerable time variation in reaching the individual stages and the duration of the individual stages. The progression of the symptomatology is reflected in the increase in symptoms appearing from the occurrence of akinetic mutism to the end stage of an apallic syndrome.Comparatively, the symptoms describing a functional loss of higher cortical functions more often occur in patients with an apallic syndrome. This difference is much more obvious in the case of the symptoms characterising a disinhibition of the autonomous functions. They occurred twice as often in patients with an apallic syndrome, except for the feature of a vegetative dysregulation which appeared as an early symptom in both groups. If the description of an apallic syndrome ${ }^{7}$ with the disturbance of the disinhibitory systems of the brain stem due to a blockage of the pallium is taken as a basis for the division of the symptoms into a complex of symptoms $1-4$ and 5-8, the conclusion is reached that decortication in patients with an apallic syndrome shows a more advanced degree of development than patients in a state of akinetic mutism. Akinetic mutism can therefore be considered as a prestage to an apallic syndrome. The coma vigile is an important distinctive feature for the diagnosis of an apallic syndrome and an akinetic mutism. The apallic patients, who are in a coma vigile, seem to be alert with eyes open but do not respond to any external stimulus. Formally, they have to be considered as being comatose. By contrast with these patients, patients in a state of akinetic mutism are alert and able to contact their surroundings, at least by eye contact. This supports the impression of an at least partly preserved activity of consciousness. On the basis of the aforementioned differences between akinetic mutism and an apallic syndrome, the complex symptomatology in patients with Creutzfeldt-Jakob disease should not be simply subsumed under the picture of an apallic syndrome. Patients with CreutzfeldtJakob disease have to be assigned to the mesencephalic form of akinetic mutism. They have to be distinguished from akinetic mutism caused by bifrontal brain damage, which creates a distinct syndrome without cognitive deficiencies or other neurological deficiencies. The term akinetic mutism has been used as a classification criterion for the diagnosis of Creutzfeldt-Jakob disease, although the term apallic syndrome would have been more appropriate for many instances. Many patients originally classified as akinetic and mute were probably already apallic. For practical reasons it is not useful to change the classification criteria. Therefore the term akinetic mutism can be applied but should be delimited clearly from the apallic syndrome as a prestage to the same. The main differences on clinical examination are: patients with an apallic syndrome (coma vigile) seem alert but without visual fixation of objects and without evident acitivity of consciousness. By contrast, patients in a state of akinetic mutism are alert with preserved visual fixation of objects. Although the spontanous speech is lost, the activity of consciousness may be evident through better speech understanding and the ability to carry out simple commands.

1 Cairns H, Oldfield RC, Pennybacker JB, et al. Akinetic mutism with an epidermoid cyst of the 3rd ventricle: with a report on the associated disturbance of brain potentials. Brain 1941;64:273-90.

2 Freemon FR. Akinetic mutism and bilateral anterior cerebral artery occlusion. $\mathcal{f}$ Neurol Neurosurg Psychiatry 1971;34:693-8.

3 Ackermann H, Ziegler H. Akinetischer Mutismus-eine Literaturübersicht. Fortschr Neurol Psychiatr 1995;63:59-67.

4 Avenarius HJ, Gerstenbrand F. Die Klinik des traumatischen apallischen Syndroms. In: Gerstenbrand F, ed. Das traumatische apallische Syndrom. Wien: Springer, 1967:9.

5 Gerstenbrand F. Das traumatische apallische Syndrom: Klinik, Morphologie, Pathophysiologie
York: Springer, 1967:23-38.

York: Springer, 1967:23-38.
6 Masters CL, Harris OA, Carleton Gajdusek D, et al. Masters CL, Harris OA, Carleton Gajdusek D, et al.
Creutzfeldt-Jakob disease: patterns of worldwide occurrence and the singificance of familial and sporadic clusterrence and the singificance of fam
ing. Ann Neurol 1979;5:177-88.

7 Kretschmer E. Das apallische Zeitschrift für diegesante Neurologie and Psychiatry 1940;169:567-79.

8 Segarra JM. Cerebral vascular disease and behavior. 1. The syndrome of the mesencephalic artery (basilar artery bifurcation). Arch Neurol 1970;22:408-18.

9 Grotjahn M. Klinik und Bedeutung akinetischer Zustände nach Luftfüllung des dritten Ventrikels. Monatsschrift für Neurologie und Psychiatrie 1936;93:121-39.

10 Mason-Browne NL. Alteration of consciousness: tumor of the reticular activating system. Arch Neurol Psychiatry 1956;76:380-7.

11 Lhermitte FC, Gautier R, Marteau R, et al. Troubles de la conscience et mutisme akinétique. Rev Neurol 1963;109: 115-31.

12 Lebrun Y. Mutism. London: Whurr, 1990.

13 Nielsen JM, Jacobs LL. Bilateral lesions of the anterior cingulate gyri: report of case. Bull Los Angeles Neurol Soc 1951; 16:231-4

14 Nielsen JM. Anterior cingulate gyrus and corpus callosum. Bulletin of the Los Angeles Neurological Society 1951;16:23543

15 Faris AA. Limbic system infarction: a report of two cases. Neurology 1969;19:91-6.

16 Buge A, Escourolle R, Rancurel G, et al. "Mutisme akinétique" et ramolissement bicingulaire: trois observations anatomo-cliniques. Rev Neurol (Paris) 1975;131:12137. 17 Kurtz D, Autret A, Ruchoux M. Mutisme akinétique
soudain et anomalies. EEG chez une femme de 89 ans. Rev Neurol (Paris) 1988;144:527-33.

18 Németh G, Hegedüs K, Molnár L. Akinetic mutism associated with bicingular lesions: clinicopathological and Neurol Sci 1988;237:218-22.

19 Borggreve F, De Deyn PP, Mariën P, et al. Bilateral infarction in the anterior cerebral artery vascular territory infarction in the anterior cerebral artery vascular territory
due to an unusual anomaly of the circle of Willis. Stroke due to an unusual

20 Lechi A, Pilleri G, Carreras M. Akinetic mutism due to glioma of the midline. Archiv für Psychiatrie und Nervenkrankheiten 1975;220:1-7.

21 Ross ED, Stewart RM. Akinetic mutism from hypothalamic damage: successful treatment with dopamine agonists. Neurology 1981;31:1435-9.

22 Shinoda M, Tsugu A, Oda S, et al. Develoment of akinetic mutism and hyperphagia after left thalamic and right hypothalamic lesions. Childs Nerv Syst 1993;9:243-5.

23 Williams D. Cerebral basis of temperament and personality. Lancet 1954;ii: $1-4$.

24 Moser A, Freyberger HJ, Bruckmann H, et al. Akinetischer Mutismus bei dekompensiertem triventrikuleren Hydrozephalus. Fortschr Neurol Psychiatr 1995;63:248-51.

25 Hochman MS, Sowers JJ, Bruce-Gregorios J. Syndrome of Hochman MS, Sowers J, Bruce-Gregorios J. Syndrome of
the mesencephalic artery: report of a case with CT and the mesencephalic artery: report of a case with CT and
necropsy findings. $\mathcal{F}$ Neurol Neurosurg Psychiatry 1985;48: necropsy

26 Brown P, Gibbs Jr CJ, Rodgers-Johnson P, et al. Human spongiform encephalopathy: the National Institutes of Health series of 300 cases of experimentally transmitted disease. Ann Neurol 1994;5:513-29. 